\title{
O espaço e o lugar na favela: as diferentes representações e identificações sobre a Favela da Maré, Rio de Janeiro
}

Cristiane Cardoso*

\section{Resumo}

As favelas têm identidades e identificações próprias, é possível distingui-las rapidamente na paisagem. A identidade é marcada pela diferença, trazem consigo uma série de símbolos que as distinguem dos demais espaços das cidades. O Rio de Janeiro é uma cidade que se constituiu através da relação diferença/ desigualdade social, política, econômica, cultural e ambiental. Estas geraram inúmeras formas e conteúdos espaciais que marcam os diferentes modos de vida, as relações estabelecidas e a maneira de "avaliar" e conceber determinados lugares. Este artigo tem por objetivo: analisar a construção das representações de ordem próxima e de ordem distante, através das diferentes linguagens (reportagens, depoimentos, fotografias, charges, desenhos, entre outros), que influenciam na formação de uma opinião pública positiva ou negativa sobre as favelas do Rio de Janeiro, em especial a Favela da Maré.

Palavras-chave: Favelas; Identidades; Representações espaciais.

** Curso de Geografia, Departamento de Educação e Sociedade da Universidade Federal Rural do Rio de Janeiro (cristianecardoso1977@yahoo.com.br).

Geosul, Florianópolis, v. 30, n. 59, p 145-166, jan./jun. 2015 
CARDOSO, C. O espaço e o lugar na favela: as diferentes representações...

Space and place in the slum: the different representation and identifications of the Favela da Maré, Rio de Janeiro

\begin{abstract}
The favelas have their own identities and it is possible to distinguish all of them in the landscape. Identity is marked by the differences by what may be or may not be. The favelas bear a series of symbols, which make them different from other spaces in the city. Rio de Janeiro is a city, which has been built up by means of social, political, economical, cultural and environmental differences and nequalities. Such inequalities have produced a large number of spatial forms and contents which have exerted directly influence on the different ways of life, on the established relationships and on the way people evaluate and conceive certain spaces in the city. This paper aims to analyzing the building up of social representations through diverse linguistic sources (reports. Interviews, photographs, cartoons, drawings, etc.) which can influence either positively or negatively in the public opinion about favelas in Rio de Janeiro and about Favela da Maré in particular.
\end{abstract} Key words: Favelas; Identity; Spatial representations.

\title{
Introdução
}

A cidade é um espaço produzido socialmente, portanto, possui realidades complexas e situações múltiplas que correspondem às políticas de ocupação, aos conflitos em relação ao uso e às contradições da apropriação social que influenciam diretamente em suas condições de existência material e simbólica.

$\mathrm{O}$ Rio de Janeiro, assim como todas as cidades que apresentam níveis semelhantes de desenvolvimento econômico e social, é uma cidade que se constituiu através das desigualdades sociais, políticas, econômicas, culturais e ambientais. Esse processo de constituição do espaço, gerou inúmeras formas e conteúdos espaciais que influenciam diretamente nos modos de 
CARDOSO, C. O espaço e o lugar na favela: as diferentes representações...

vida, nas relações estabelecidas e na maneira de "avaliar" e conceber determinados lugares. Assim, as trajetórias de vida, as relações com o lugar e as representações do espaço resultam em diferentes percepções urbanas, que podem ser positivas ou negativas, dependendo dos atores que as concebem e as vivenciam.

As favelas surgem em decorrência da ocupação dos "chamados" espaços vazios da cidade, desvalorizados pelo setor imobiliário. A especulação imobiliária faz com que as pessoas desprovidas das condições sociais e materiais necessários se instalem em áreas "menos atrativas", tais como encostas e manguezais. Nos 111 anos de existência desses espaços várias políticas foram implantadas tentando resolver o "grande problema" que essas ocupações produziram na cidade. Porém, foram desiguais as tentativas de melhorar as condições de vida dos homens, mulheres e crianças das favelas e não produziram os efeitos desejados.

As favelas, tal qual são concebidas, constituem espaços dentro da cidade, marcados pelo medo, pela violência, pelas ausências, sendo expressão do caos urbanístico (informal e sem regras de construção). No entanto, para quem as vivencia, mais do que representar os espaços da violência, as favelas são verdadeiros lugares, no qual estão cristalizadas relações pessoais e sociais, marcadas principalmente por laços afetivos e pela experiência mútua.

Diante da complexa e contraditória realidade das favelas, múltiplos são os discursos que as revelam, alguns tentam ocultar o preconceito tentando justificar as ações do poder público, outros reafirmando a dualidade favela-cidade, mas revelando determinadas presenças: alegria, solidariedade, carnaval e dos grandes sambas que desceram a ladeira e ganharam.

Este artigo tem como objetivo analisar os diferentes conflitos entre o concebido, percebido e vivido existentes na produção do espaço, e o processo de criação das representações e identidades sobre o lugar e do lugar chamado favela. 
CARDOSO, C. O espaço e o lugar na favela: as diferentes representações...

Para o desenvolvimento da pesquisa utilizamos de analise de referencial teórico sobre a temática, trabalho de campo com registros fotográficos e entrevistas com roteiro semiestruturado e acompanhamento das aulas do observatório de favelas. Trata-se de uma pesquisa qualitativa na Favela da Maré, localizada no Rio de Janeiro, partindo das vivências e experiências de 40 jovens e adolescentes moradores desta favela. $\mathrm{O}$ objetivo foi visualizar discursos e representações produzidos por estes moradores, 0 "olhar de ordem próxima", numa tentativa de resgate da identidade local, mostrando uma representação contra-hegemônica proveniente da vivência direta destes lugares, não se tem como objetivo extrapolar estes resultados como padrão para todas realidades das favelas.

\section{O espaço e o lugar da favela: conflitos entre o concebido, percebido e o vivido}

O espaço é produzido pelas diferentes ações e práticas sociais dos indivíduos, que o modificam através do trabalho e da tecnologia em função de suas necessidades sociais, econômicas, políticas e ambientais. O espaço não é fixo, possui fluxos e uma série de formas, funções, estruturas e processos marcados temporalmente. Ele constantemente é (re)significado e adquire novas funções alterando sua configuração, no sentido que

as novas atividades exigem um lugar no espaço e impõem uma nova arrumação para as coisas, uma disposição diferente para os objetos geográficos, uma organização do espaço diferente daquela que antes existia" (Santos, 2002, p. 205).

Desta maneira, o espaço não é estático, possui uma fluidez, e apresenta uma adaptação dos objetos e das pessoas ao processo produtivo, de modo que suas características alteram-se ao longo do tempo e através da escala espacial.

A cidade do Rio de Janeiro é um exemplo deste espaço não estático. Com a cidade estabelecida, vários projetos e reformas 
CARDOSO, C. O espaço e o lugar na favela: as diferentes representações...

foram e ainda são produzidos para remodelar, dar novas funções e dinamizar bairros, praças e prédios. Formas e funções se alteram, e com elas os processos e estruturas. $\mathrm{O}$ velho e o moderno hoje se apresentam simultaneamente, basta seguirmos pelas principais avenidas do centro da cidade, como a Presidente Vargas e Rio Branco para visualizarmos estes aspectos. As funções também não são mais as mesmas, algumas foram sedes administrativas e se transformaram em residências ou estabelecimentos comerciais e financeiros. A valoração do centro da cidade também mudou ao longo do tempo: já foi visto como um local de trabalho, moradia, indústrias, escolas. Hoje, é basicamente local de trabalho e de setores econômicos e financeiros.

Neste contexto, as favelas também têm sua dinâmica, de modo geral essas áreas num primeiro momento, abrigaram pessoas que chegavam de outros lugares, e em maioria população pobre vinda dos cortiços e de outros locais "menos nobres" da cidade desprovida de capital para habitar lugares destinados ao mercado formal. A população moradora teve que construir estes espaços com uma arquitetura que desafia qualquer projeto de arquitetura, engenharia e planejamento oficial. Hoje, a favela está presente em qualquer cidade, seja de pequeno, médio ou grande porte e abriga uma população historicamente segregada e hoje luta pelo seu direito de habitar a cidade.

As favelas foram formas de habitações "alternativas" de morar, sendo a única forma encontrada pela população que precisava "habitar" a cidade e não tinha recurso financeiro para comprar um "lote" regularizado pelo governo. Kowarick (2000) comenta que estas habitações surgem como alternativas compensadoras para fugir dos aluguéis e de, certa vulnerabilidade que eles conferem; já que a casa própria, mesmo sendo localizada e construída em locais não legalizados, é uma garantia de abrigo nos momentos de crise. Desta forma, estas áreas que não possuem valor comercial, social e simbólico, que são desprovidas de atrativos e com limitações muitas vezes físicas e expostas a risco ambiental (por exemplo, a declividade do relevo e/ou inundação 
CARDOSO, C. O espaço e o lugar na favela: as diferentes representações...

pelas marés), foram abandonadas pelas classes sociais mais favorecidas financeiramente e ocupadas pelas desfavorecidas. $\mathrm{O}$ caráter de Alternativo se revela quando se remete às características construtivas e arquitetônicas, que conformam sua forma e aparência. Essas moradias, decorrem da autoconstrução, que ocorre quando uma casa faz parte do projeto de vida de uma família que constrói sua habitação com a ajuda de parentes e amigos. As construções das favelas são alternativas porque apresentam estruturas diferenciadas das casas e apartamentos do setor formal de habitação; na favela a verticalização é resultado do aproveitamento dos espaços. Como não existe muita área física disponível, a expansão vertical aconteceu, abrigando a própria família, ou destinada à obtenção de uma renda extra (aluguel, ou venda da laje).

A ocupação da favela foi de certa forma "permitida", quando foram "cedidos" espaços para construção ou quando não houve uma política eficaz para conter o avanço destas ocupações. Permitida, porque, desde o seu surgimento, foi estabelecida com o consentimento dos governantes, que "reservaram" algumas áreas para a formação do que seria mais tarde a primeira favela do Brasil (Morro da Providência), no primeiro momento destinado para os militares que retornavam da Guerra dos Canudos, no segundo momento era ocupado pela população removida pela demolição dos cortiços (época conhecida como Bota-abaixo) e, mais tarde para a população que não tinha para onde ir e precisava ficar próxima ao local de trabalho. Também foi permitida por todos os setores da sociedade que precisavam desta população para os diversos serviços (trabalhos domésticos, construção civil, lavadeiras, porteiros, entre tantos outros) e não queriam ter muita despesa com o transporte dos empregados.

Algumas favelas ou moradas populares foram frutos de um planejamento do governo buscando "construir novas moradias" para solucionar problemas habitacionais de outros lugares do Rio de Janeiro, para abrigar a população removida de áreas nobres da cidade ou para retirá-la da área de risco em que se encontravam. $\mathrm{O}$ 
CARDOSO, C. O espaço e o lugar na favela: as diferentes representações...

local não foi dotado de infra-estrutura básica, tal como transporte público para o deslocamento, coleta de lixo, oferta de trabalho próximo, escolas, hospitais, entre outros. Algumas comunidades como a Nova Holanda, Conjunto Esperança, Vila Kennedy e Cidade de Deus foram construídas pelo governo, algumas destinadas a habitações provisórias e outras permanentes. Porém, foram projetos concebidos pelo "olhar do outro", isto é, dos planejadores que achavam que o importante era ter um "teto", um local para alocar as famílias. A favela, muitas vezes, foi e é concebida por ações do Estado, que por meio de normas urbanas "legais" construiu algumas áreas, desrespeitando as "estratégias criativas, complexas e heterogêneas (Silva e Barbosa,2005)." realizadas pelos moradores para sobreviver na cidade. Destacam-se como exemplo os "puxadinhos", ou as lajes, que têm um papel fundamental tanto no econômico (ampliação da casa, venda do espaço vertical) quanto social (área de lazer, espaço de reunião familiar e de amigos). Desta forma, os moradores "permanecem, em geral, na condição de objetos dos responsáveis pelas intervenções", como salientam Silva e Barbosa (2005, p. 65).

Atualmente ainda percebemos claramente esta política; o programa favela bairro é um exemplo de intervenção, ou melhor, de concepção e percepção dos espaços populares pelos planejadores. Sem a devida participação dos moradores, muitas obras servem apenas para "maquiar" a realidade da favela, pois parece que os planejadores simplesmente acreditam que o calçamento, a rede de esgoto, a legalização da propriedade e a transformação em bairro resolverão todos os problemas das comunidades. Na verdade, é mais uma forma de poder sobre estes espaços, isto é, uma forma de "controle", seja político, econômico, social ou ambiental, assim como de expansão física.

Pensar em uma habitação popular implica em admitir a diversidade e as especificidades de cada lugar, assim como avaliar as condições socioeconômicas de seus moradores. Não basta construir projetos legais com padrões residenciais concebidos, com controle do espaço construído, da circulação e reprodução das 
CARDOSO, C. O espaço e o lugar na favela: as diferentes representações...

práticas sociais. Nos espaços populares de habitação, as casas adquirem funções múltiplas vinculadas ao trabalho e à renda, como forma de superar as adversidades do cotidiano (falta de emprego formal, baixos salários, distância do emprego, entre outros). Perlman (1977, p. 40) ao abordar a favela constata que por dentro "a construção das casas leva em conta o conforto e a eficiência, tendo em vista o clima e os materiais disponíveis". Aborda ainda o orgulho e afeto que as pessoas tem por sua casa e por suas coisas, mostrando uma identidade fundamental para com o lugar.

A aparência da favela reflete diretamente o cotidiano da comunidade, seu espaço em constante movimentação marca as diversas formas encontradas pela população para sobreviver e habitar a cidade. A lógica do mercado formal não é a mesma do chamado "informal", no sentido que uma casa na favela pode ser a síntese de uma vida (pode se levar mais de 10 anos para construir uma casa), enquanto nos bairros formais é fruto de uma escolha ou condição financeira pessoal.

Durante anos, as favelas e os conjuntos habitacionais não foram prioridade para os governantes, estes não destinaram verbas para melhorar as condições de vida desta população em nenhuma dimensão, seja social, cultural, econômica ou ambiental.

\section{As representações e as diferentes identificações sobre o espaço vivido}

Ao longo de sua existência a favela foi percebida e concebida de diferentes formas. Seu espaço foi marcado por representações criadas, recriadas, significadas e (re)significadas pelos diversos setores da sociedade (mídia, governo, cidadãos) e não por seus moradores. Lefebvre (1983) afirma que toda representação implica em um valor, este pode ser definido a partir do que está presente ou ausente, pelo que é valorizado ou desvalorizado por um determinado setor que detém poder. Dessa forma, nas favelas, as ausências foram fundamentais para caracterizá-las e identificá-las. A ausência do Estado que vai desde 
CARDOSO, C. O espaço e o lugar na favela: as diferentes representações...

a implantação e manutenção de infra-estrutura básica, até as ações como segurança, educação e saúde, criaram estas representações das ausências e trouxeram valores relacionados a algo ruim, como o medo e a desordem.

Nas representações estão envolvidos vários discursos e linguagens, que podem ou não estar ligados ao poder, relacionados à ordem próxima (interna) e distante (externa). Assim, se as favelas são espaços nos quais está contido o percebido e o concebido, como também o vivido, por que as ausências foram tão marcantes na construção de sua identidade?

Ao longo do século XX, percebemos claramente que a mídia teve um papel importante na dispersão dos estereótipos de favela que não correspondem exatamente à realidade da favela; as representações realizadas sobre estes espaços são difundidas para justificar determinadas práticas sociais, econômicas, políticas e ambientais sobre eles.

As remoções, demolições e a utilização da força policial nestes espaços são concebidas pelos governantes, que se utilizam dos meios de comunicação para justificar suas ações. A mídia torna-se um instrumento capaz de contribuir de forma significante na formação de opiniões sobre esses espaços. Não que as pessoas absorvam todas as informações como verdades absolutas. Contudo a mídia contribui para conceber e perceber os espaços que são desconhecidos ou não vivenciados diretamente por todos.

Os meios de comunicação não são neutros, eles têm o papel de selecionar, editar, classificar e opinar. Portanto, é a partir da tendência política- ideológica de cada meio que as realidades passam a ser produzidas, e, dessa forma é o conceito de favela aceito, principalmente por quem não tem a vivência do lugar. A informação que o repórter coleta já é filtrada por suas percepções individuais, depois essa informação passa pela lente da pauta do dia, pela seleção do editor chefe e, tudo isso permeado pela tendência ideológica do jornal. Os meios de comunicação [geralmente] massificam e uniformizam a diversidade. D. (35 anos, morador do Parque Maré) tem a nítida noção das 
CARDOSO, C. O espaço e o lugar na favela: as diferentes representações...

representações difundidas pela mídia: "ela pode influenciar na opinião veiculando e repetindo estereótipos e preconceitos", a fim de perpetuar e demarcar as diferenças sociais no espaço urbano.

Os aspectos positivos que os moradores gostariam de ver nos noticiários são considerados exceções. Qualquer projeto social é concebido como uma solução e salvação para seus moradores. A reportagem "Virada cultural carioca" da revista $O$ Globo do dia 4 de julho de 2006 inicia a matéria desta forma: "As favelas do Rio estão promovendo uma virada cultural pra transcender a miséria e a violência". Como se a solução dos problemas relacionados à miséria e à violência fosse somente pelo lado cultural. Silva e Barbosa (2005, p. 109) comentam a respeito de alguns projetos que "aportam" nas comunidades, cujo objetivo é "tirar os jovens do domínio do tráfico de drogas, como se todos os jovens fossem potencialmente violentos e criminosos". Tais projetos já começam de maneira preconceituosa, com uma visão assistencialista (grande mito das necessidades e das ausências que devem ser minimizadas) e só contribuem para o fortalecimento das representações negativas sobre estes espaços, sejam áreas de favelas ou não.

As representações criadas e difundidas são repassadas para as pessoas, que concebem e percebem estes espaços de maneira irreal, através do olhar do outro (ordem distante). Esta visão é muito clara quando perguntamos aos entrevistados o papel da mídia nas representações sobre as favelas: 96\% deles declaram que a mídia influencia na visão das pessoas que não vivenciam estes espaços.

Acredita-se que a mídia seja um mecanismo responsável pela formação de opinião das pessoas, massificando visões e sentimentos, sejam eles positivos ou negativos. Estes discursos auxiliarão na construção de uma representação coletiva da "população do asfalto" que não vivencia diretamente os problemas e as virtudes do lugar, porém, constrói uma imagem sobre a favela.

Direta ou indiretamente, as pessoas estão se questionando a respeito da tríade que Lefebvre (1983) julga fundamental para a produção do espaço urbano: as relações entre vivido, o percebido e 
CARDOSO, C. O espaço e o lugar na favela: as diferentes representações...

o concebido. Ao salientar estas falas, reportamo-nos ao papel das representações estabelecidas pelo que é concebido e pelo que é percebido. Um olhar externo, sobre o outro, sob uma determinada ótica que é capaz de massificar sentimentos e opiniões. Os moradores falam que jamais deveriam ser esquecidas as experiências para com o lugar, isto é, as relações vivenciadas por eles na favela.

Quando a referência é o "eu", a identidade, isto é, a capacidade que a mídia tem de influenciar a visão interna sobre a comunidade, $78 \%$ dos entrevistados afirmam que não são afetados pela imagem de favela construída pelos meios de comunicação. Contra isso, argumentam que conhecem o lugar e sabem o que acontece de fato (relação com o espaço vivido). Entretanto, 22\% afirmam que são influenciáveis pelas notícias, porque as informações são veiculadas todos os dias e podem ampliar a sensação do medo e da insegurança. A. (22 anos, morador do Parque União) comenta: "pode influenciar na minha opinião através do teatro que é feito, da situação de caos, quando mostra a favela e associa a essa imagem e, mesmo não querendo, a gente incorpora essa visão". Apesar de ter a noção destas representações difundidas, ele afirma que é influenciável, pois, quando somente aspectos negativos são repassados, passamos a incorporá-los como verdades. Desta forma, o percebido e o concebido influenciam e contribuem nas representações sobre o vivido.

A relação entre o feio e o bonito, isto é, a valoração de lugares frente a uma determinada concepção de mundo também está presente nos discursos como o de C. (16 anos, morador da Baixa do Sapateiro), que acha que a cidade é muito bonita, mas tem partes que são feias, e refere-se à favela como sendo o lado "ruim" e "feio" da cidade: "tem muitos locais legais e bonitos como as praias, mas tem outros que não, como as favelas". $\mathrm{Na}$ visão dele, a favela é feia porque não possui o "padrão" estético que foi utilizado em outros bairros formais (arruamento, casas pintadas, áreas verdes, entre outros elementos). Este padrão estético é marcado por uma concepção sobre como devem ser os 
CARDOSO, C. O espaço e o lugar na favela: as diferentes representações...

espaços urbanos. Novamente percebemos a representação do concebido classificando as áreas e modificando e desvalorizando o vivido.

A luta desleal está relacionada ao direito de habitar, de morar na cidade de maneira igualitária, que não se reduz a ter direito a uma casa. A desigualdade, nesse sentido, está relacionada aos direitos fundamentais de cada cidadão: existência e acesso aos serviços sociais básicos, circulação na cidade (indo além dos trajetos diários casa-serviço), segurança, entre tantas outras formas existentes.

As representações sobre os espaços populares relacionadas às ausências (o que ela não possui) e à criminalidade (todos estão propensos ao crime ou fazem parte dele) se materializam através do concebido hegemônico, principalmente quando seus moradores são tratados como não-cidadãos (porque são indesejáveis, suspeitos) ou, ainda, como sub-cidadãos (desejáveis porque contribuem para uma série de serviços não prestigiados - faxineiro, porteiro, vendedor ambulante, entre outros).

Lyrio (2005) comenta sobre a hierarquização territorial existente para esta população e a discriminação vai se naturalizando

se naturalizam que os moradores da favela devam estar inseridos socialmente apenas através da ocupação de postos de trabalhos pouco qualificados ou subalternos. Ou ainda, quando passam a orientar projetos voltados para a ocupação da ociosidade, como forma de escapar do mundo do crime e/ou das drogas, (pré)supostamente o caminho natural dos moradores da favela.

Observamos que as representações dos espaços influenciam o olhar de dentro e de fora (ordem próxima e distante). Muitas vezes as pessoas que vivenciam os lugares não percebem esta reprodução do discurso. É muito tranqüilo identificar os símbolos para a cidade e para um lugar a partir do que já está concebido. Pode-se observar claramente estas reproduções ao falarmos dos símbolos da cidade. No entanto, quando buscamos os significados 
CARDOSO, C. O espaço e o lugar na favela: as diferentes representações...

do lugar (favela da Maré) a partir do vivido, do que poderia ser concebido e percebido pelo olhar de dentro, percebemos uma grande dificuldade em criar uma representação pessoal nas resignificações do espaço da favela. A grande dificuldade estava em relacionar um símbolo (que não estava pronto, isto é não foi dada nenhuma opção) que identificasse a favela. O discurso de R. (45 anos, moradora do Pinheiros)." "aqui não tem nada, nada é bonito, nada marca este local, falta tudo", demonstra esta afirmação. R. vive na comunidade há 35 anos, mas não gosta de viver ali, faz uma relação imediata da favela com o lugar do medo, da falta de lazer, de educação, saúde. O bonito para ela está relacionado às formas e estruturas que encontramos nos bairros da Zona Sul, isto é, o que é representado como algo seguro, limpo, tranqüilo e organizado.

Os símbolos presentes nos discursos, quando identificados, foram bem diversificados: aspectos físicos, sociais (como a Vila Olímpica e as casas), os problemas vivenciados (entrada do carro blindado - caveirão - da polícia), e subjetivos como a paz e a espontaneidade das pessoas.

As formas encontradas para habitar as favelas também são reconhecidas por seus moradores. Frutos ou não do percebido e concebido, são diretamente relacionadas ao vivido. Uma das características que identificam as favelas são as aparências de suas casas marcadas pela autoconstrução, isto é, são geralmente idealizadas, planejadas e construídas pelos próprios moradores, sem um planejamento urbano formal e assistência técnica de engenheiros ou arquitetos. Estas casas foram reconhecidas como algo que é diferente do espaço formal, associado aos grandes capitais imobiliários, e foram definidas como símbolos pelos seus moradores, como J. (20 anos, moradora da Maré): "as casas são um símbolo, elas mostram de cara, o que é a favela". Logicamente, esta identificação não está relacionada somente a forma e à aparência das casas, está relacionada também à disposição, ao arruamento e à comunidade como um todo. 
CARDOSO, C. O espaço e o lugar na favela: as diferentes representações...

As manifestações culturais estão presentes nestes lugares e são citadas pelos moradores como algo muito bom presente nas comunidades, como podemos observar na fala de C. (23 anos, moradora do Parque União): "eu representaria a favela com um casal dançando, o forró é uma marca do Parque União, é forró de segunda a segunda". Apesar da falta de investimentos público e privado em atividades culturais e de lazer nas favelas, a própria comunidade encontra formas de superar estas adversidades, participando e organizando as festas nas ruas, os shows nas praças e os campeonatos de futebol entre as comunidades. As ausências (dos governantes) implicam em outras formas de presenças na favela, marcadas principalmente pela solidariedade e vivência das pessoas. Estes locais são marcados pela alegria, outro símbolo que foi salientado em algumas entrevistas, como é o caso de A. (20 anos, moradora do Parque União): "eu escolheria a alegria, porque apesar de toda esta falta do governo as pessoas são solidárias e felizes".

A beleza e a tranqüilidade também aparecem como símbolos. S. (16 anos, morador do Parque União) faz um comentário sobre este aspecto: "o nascer do sol por cima do morro dá a idéia de que um novo dia venha, e com ele novos momentos emocionantes, que darão prazer de morar na favela". Ele faz uma relação direta entre o sol e a resolução dos problemas, uma renovação constante baseada no ritmo da natureza.

Estes símbolos são representações da favela vivenciadas pelo olhar de ordem próxima, isto é, olhares dos seus moradores calcados na experiência afetiva ou não da favela. São reflexões que marcam o cotidiano, que são carregadas de significados e aspirações. São os mundos individuais e coletivos que são compartilhados, é a vida que se realiza a partir da "mediação com o outro". Cada agente da produção do espaço tem a sua representação sobre ele (Lefebvre, 1983). Se por um lado, a favela é um espaço concebido e percebido pelos governantes e pelas pessoas que contribuem para a construção de visões estereotipadas, por outro, os moradores da favela querem representá-la de outra 
CARDOSO, C. O espaço e o lugar na favela: as diferentes representações...

forma, querem basear seus olhares nas suas vivências, nas presenças, como forma de garantia de sua existência.

A violência também é enxergada como um símbolo e é uma forma que as pessoas encontram para representar estes espaços. $\mathrm{O}$ símbolo pode trazer um sentimento positivo ou negativo. L. (20 anos, morador do Conjunto Esperança) fala do tiroteiro na Linha Vermelha, que faz com que a Maré apareça nos noticiários e seja instantaneamente identificada: "tem o tiroteiro na Linha Vermelha, todo mundo fica sabendo que é aqui na Maré, é fácil de localizar". As representações que os entrevistados fazem da favela são semelhantes e se relacionam ao que é repassado pelos meios de comunicação sobre as favelas. São reproduções dos discursos marcados pela violência e pelo medo, já que o medo é um mecanismo de não ação. É uma forma de controle social que se dá de fora para dentro e na própria favela.

As estruturas relacionadas a centros culturais e educacionais também são citadas como símbolos, como é o caso do Centro Estudos e Ações Solidárias da Maré (Ceasm), citado por E. (16 anos, moradora da Nova Holanda): "é um lugar de estudo, onde se entra burro e sai inteligente". Penso que a expressão "entra burro" evoca o sentimento de impotência e de inferioridade que algumas pessoas possuem na comunidade, presente em inúmeros discursos, inclusive de profissionais ligados à educação. Em locais como o Ceasm e em algumas instituições de ensino, existe uma valorização da pessoa como um sujeito ativo e participativo de todo o processo de ensino-aprendizagem (um aproveitamento das vivências e experiências individuais) e uma valorização da cidadania. Por intermédio do resgate histórico de sua origem e das comunidades, da valorização do sujeito diante do lugar de moradia, entre outras ações, está sendo possível re-significar diversas práticas sociais de jovens e adultos das comunidades.

Os símbolos, para os entrevistados, estão associados aos lugares que são sinônimos de orgulho, locais que gostariam que todas as pessoas conhecessem e vivenciassem. A Vila Olímpica, a Praça do Parque União, o Parque Ecológico, a própria casa, o 
CARDOSO, C. O espaço e o lugar na favela: as diferentes representações...

Morro do Timbau, algumas instituições culturais e educacionais (Ceasm, Observatório de Favelas, CIEP, entre outros), a feira, campo de Rubens Vaz, o forró, entre tantos outros, foram apontados como lugares bons e interessantes para levar alguém "de fora". São locais que ajudam a des-construir e a re-significar as comunidades que compõem a Maré, seja por conterem uma história, por serem lugares tranqüilos, lugares de lazer, espaços neutros e organizados, ou simplesmente porque retratam $o$ cotidiano.

A experiência humana através do uso do espaço (vivido, percebido e concebido) passa por diferentes visões sobre este lugar, no caso da Maré, diferentes representações sobre este espaço. Neste trabalho, buscou-se compreender a visão que os jovens tinham a respeito das favelas, em seu lugar de morada.

A maior parte deles fala que a favela é um lugar muito bom para se morar, possui muitas alegrias, um local no qual eles criam seus meios de diversão (encontramos muitas crianças jogando futebol nas ruas, eles mesmos pintam as ruas e montam o campo), porém admitem que a violência esteja muito presente, principalmente no conflito entre traficantes e policiais. M. (15 anos, morador da Baixa do Sapateiro) define a favela assim: "tem vezes que é tranqüila, mas tem vezes que sai tiroteiro, a Maré é igual a outras favelas, com bandidos, como a Vila Olímpica, PM matando gente...". Quando ele utiliza o termo "igual a outras favelas", acaba tornando o local homogêneo e não percebe as suas particularidades e suas especificidades; para ele, a favela é um lugar onde a violência está presente, seja pela ação dos bandidos ou pela ação dos policiais.

V. (31 anos, morador da Nova Holanda) comenta: "para mim a favela é muito boa, mas devido à violência fica perigosa, depois do blindado ficou mais perigosa ainda, eles atiram em inocentes. A Maré é um bom lugar para se viver". O lugar ganha um sentido de algo experienciado, amado, dotado de valores e significados (Tuan, 1983). Apesar de Vinícius ter noção da violência que o cerca, a favela da Maré ainda é o seu lugar, não deixa de ser um 
CARDOSO, C. O espaço e o lugar na favela: as diferentes representações...

lugar bom para se viver. É impressionante o papel que o blindado da polícia tem no discurso dos jovens e crianças, que demonstram muito medo e revolta pela forma com que a polícia militar realiza suas incursões dentro das comunidades.

Ao falar da favela da Maré, V. (20 anos, morador da Baixa do Sapateiro) comenta que a favela é uma moradia associada à falta de recursos da população, que não consegue habitar em outros espaços da cidade: "local de moradia de trabalhadores, que permanecem nestes locais a vida inteira por não terem condições financeiras para custear um melhor padrão de vida". Ele mostra um sentimento de inconformidade com a situação que as comunidades enfrentam (pensando nos problemas vivenciados) tendo uma noção do papel do setor imobiliário, com o apoio do setor público, que regulariza o uso sobre a cidade, e do "controle" exercido pela força policial sobre estes lugares.

F. fala da espontaneidade destes lugares: "espaço espontâneo, cada um vive como quer, com seu jeito de ser". A espontaneidade está presente no jeito de ser das pessoas, mas também é composta pelas obras, pela arquitetura, pelos espaços construídos para a diversão, como salienta C. (22 anos, moradora do Parque União): "a favela pode ser identificada pelo emaranhado de casas, raças, cores, que fazem dela algo especial”. A diversidade é que compõe a unidade, isto é, a favela.

R. (16 anos, morador do Parque União) estabelece uma relação entre "dentro" e "fora", associada a pertencer ou não ao lugar: "odiada por muitos, amada por mim". Este odiada por muitos se refere ao "olhar de fora", sobre as representações que se faz sobre estes espaços populares. D. define a favela da Maré desta forma: "é a minha comunidade, que não é o paraíso que eu quero, mas também não é o inferno que a mídia apresenta, a Maré é grande, diversa, desconhecida (para os de dentro e de fora), e animada".

A existência de comércio e de condução - mesmo que não formais - também foram citadas ao falar da favela, mostra que muitas vezes a população não precisa buscar estes serviços fora das 
CARDOSO, C. O espaço e o lugar na favela: as diferentes representações...

comunidades. Apesar de muitas coisas tornam-se mais caras do que as encontradas em outros bairros, esta prática é comum porque há uma série de "facilidades" para a aquisição, como o crédito local (sistema de cadernetas ou de pagamento mensal) e a proximidade no deslocamento.

\section{Considerações finais}

O espaço no qual está sitiada a cidade do Rio de Janeiro foi construído de forma desigual. Cada uma delas é resultado de políticas governamentais implantadas que foram privilegiando determinados lugares em detrimento de outros. Conhecemos e vivenciamos diariamente os resultados dessas práticas que resultaram nas desigualdades sociais, culturais, econômicas, políticas e ambientais que marcam a cidade. As favelas surgiram nesse deste contexto de desigualdade e contradições.

As relações sociais estabelecidas e as vivências (experiências) associadas ao sentimento de estar em comunidade farão com que surjam movimentos contrários aos discursos hegemônicos sobre as favelas (espaços homogêneos, das ausências, da violência, entre outros). São representações de ordem próxima, tiradas do cotidiano das pessoas. Essas representações buscam mostrar outra vertente, reafirmando as diferenças e a realidade, mas mostrando outro lado da favela.

As favelas trazem consigo uma série de símbolos que as individualizam em relação aos demais espaços da cidade, símbolos que podem ser marcados pelas ausências, concebidas e percebidas pelo outro, cujo discurso se faz em oposição: favela e asfalto. São identificadas pela sua aparência (disposição, formas de suas casas), pela sua localização (morros, áreas alagadas), pela falta de registro oficial regulamentando a habitação (título de propriedade), pela precariedade na sua infra-estrutura, entre tantos outros elementos. A favela é identificada pelo que ela não é e pelo o que não possui em relação ao outro (asfalto). Algumas presenças são enfatizadas, 
CARDOSO, C. O espaço e o lugar na favela: as diferentes representações...

como a violência (como resultado das condições de vida consideradas precárias).

Através das relações e práticas espaciais estabelecidas (trabalho, participação social) o homem vai se "produzindo", tornando-se um sujeito integrado. O espaço vivido adquire novo significado e nova identidade. Na medida em que nos apropriamos dos diferentes significados que a cidade possui, criamos e reconstruímos uma rede de lugares, através do uso de linguagens, comportamentos e práticas. Criar uma rede de lugares significa estabelecer vínculos e laços, sejam eles afetivos ou estreitamente profissionais, significa dar um significado particular e próprio para algumas áreas da cidade.

As identidades são "construídas" pelas pessoas, são fontes de experiências de uma população para com um determinado espaço geográfico, no que tange às suas características comuns e compartilhadas por esses atores. As identidades e identificações nas favelas são marcadas tanto pela nomenclatura das ruas, dos becos e bares, que têm um significado para seus moradores, quanto de âmbito mais geral, que passa envolver formas de vestir e falar, os lugares ganham as especificidades.

A favela, para quem a vivencia, é um lugar de morada, cheio de riquezas, laços familiares, repleto de recordações. Quem vivencia estes espaços tem uma percepção bem diversificada e consegue visualizar todas as diferenças e retratá-las de outra maneira, como é o exemplo de muitos sambas, caricaturas, desenhos em grafites, poesias, músicas, entre tantas outras linguagens. As representações internas, logicamente, serão diferenciadas, isto é, são marcadas por outros símbolos, por estas vivências, pelas identidades e identificações para com os lugares, porém elas nunca são totalmente baseadas somente nestas vivencias, elas são resultados de todas as escalas do conhecimento: vivido, percebido e concebido. 
CARDOSO, C. O espaço e o lugar na favela: as diferentes representações...

\section{Referências bibliográficas}

ABREU, M de A.. Reconstruindo uma história esquecida: origem e expansão inicial das favelas do Rio de Janeiro. Revista Espaço e Debates. No $37,1994.34-46 p$.

BARBOSA, J. L. A arte de representar como reconhecimento do mundo: o espaço geográfico, o cinema e o imaginário social. Revista Geographia. Ano II, no 03, 2000. pp. 69-88.

CARLOS, A. F. A. O espaço Urbano - novos escritos sobre a cidade. São Paulo: Contexto, 2004.

CORRÊA, R. L. Espaço, um conceito-chave da Geografia. In: CASTRO, Iná Elias de; GOMES, Paulo César da Costa \& CORREAA, Roberto Lobato (orgs). Geografia Conceito e temas. $2^{\text {a }}$ Ed. Rio de Janeiro, Bertrand Brasil, 2000.p.15-47.

CEASM. A Maré em dados: Censo 2000. Rio de Janeiro, 2003.

FRÉMONT, A. A região, espaço vivido. Trad. Antônio Gonçalves. Coimbra: Almedina, 1980.

JARDIM, A. de P. A espacialidade construída pelo olhar da modernidade. Resenha dos cap. I, II e V do livro A vida cotidiana no mundo moderno, Henri Lefebvre. 1996, inédito.

LEFEBVRE, H. La presencia y la ausencia - contribución a la teoría de las representaciones. México: Fondo de cultura económica, 1980.

. The Production of Space. Translated by Donald Nicholson-Smith. Cambridge, Massachusetts: Blackwell Publishers, 1991. 
CARDOSO, C. O espaço e o lugar na favela: as diferentes representações...

Paulo: Centauro, 2001.

O direito à cidade. Trad. Rubens Eduardo Frias. São

LYRIO, W. Os Limites Territoriais e as Fronteiras da Alteridade em Espaços Populares: um estudo das territorialidades na Maré. Rio de Janeiro, 2005. p. Dissertação (Mestrado em Geografia). Curso de Pós-Graduação em Geografia, Universidade Federal Fluminense.

MOSCOVICI, S. Representações Sociais. Trad. Pedrinho A. Guareschi. Petrópolis, RJ: Vozes, 2003. 40.

NASSEY, D. Um sentido Global do lugar. In: O espaço da diferença - ARANTES, A A (org). Campinas, SP : Papirus, 2000. p.p.177-185.

PERLMAN, J. E. O mito da marginalidade: favelas e política no Rio de Janeiro. Rio de Janeiro: Paz e Terra, 1977. 377p.

ORTIZ, R. Cultura Brasileira e identidade nacional. 5a Edição. São Paulo: Brasiliense, 2003.

SANTOS, M. Metamorfose do espaço habitado. 4 ed. São Paulo: HUCITEC, 1997. 124 p.

. O Lugar e o cotidiano. In: A natureza do Espaço: Técnica e tempo, razão e emoção. São Paulo: Editora da Universidade de São Paulo, 2002. 313-330p.

SILVA, J de S \& BARBOSA, J. L. Favela Alegria e dor na cidade. Rio de Janeiro: Senac Rio Editora, 2005. 232p.il.

TUAN, Yi-Fu. Espaço e lugar - a perspectiva da experiência. Trad. Lívia de Oliveira. Rio Claro: Difel, 1930. 250p. 
CARDOSO, C. O espaço e o lugar na favela: as diferentes representações...

VARELLA, D. et. al. Maré, vida na Favela. Rio de Janeiro: Casa da Palavra, 2002.

ZALUAR, A. \& ALVITO, M. (orgs). Um século de Favela. Rio de Janeiro: Editora Fundação Getúlio Vargas, 1998. 372p.

WOODWARD, K. Identidade e diferença: uma introdução teórica e conceitual. In: Identidade e Diferença- a perspectiva dos estudos culturais. SILVA, T. T; HALL, S \& WOODWARD, K. Petrópolis, RJ: Vozes, 2000. 07-72p.

Recebido em janeiro de 2015 Aceito em abril de 2015 